\title{
Behavioral parameters of social dominance in rats
}

\author{
J. MARTIN RAMIREZ \\ Stanford University, Stanford, California 94305
}

\begin{abstract}
The present experiment studies the social dominance in rats, analyzing several agonistic and nonagonistic behavioral parameters. A correlation was observed within the agonistic categories, revealing also a positive correlation with the general bodily activity. However, it is noted that since dominance hierarchy in rats is not unidimensional, but complex, a further study of other factors influencing behavior is required in order to enable general conclusions regarding social behavior.
\end{abstract}

It has been stated that social dominance in rats is demonstrated by the release of submissive behavior in group mates as well as in the priority rights an animal possesses in front of others during the approach situation and by avoiding negative experiences (Militzer, 1977). More than a half century ago it was established that the social rank of a hen is predominantly linear and depends upon its aggression against others (SchjelderupEbbe, 1922). This "pecking order" became very popular and has since been used as a parameter for measuring social rank order in a variety of species.

Agonistic behavior, including attack, threat, submission, and withdrawal (Martin Ramirez \& Delius, 1979a, 1979b), should be, then, an essential factor in social dominance; however, it has only been suitable as a measure of dominance when animals with high aggressive tendencies have been tested. Moreover, it is well known that aggression usually is reduced in permanent social animal colonies. Besides the typical agonistic patterns, other behavioral activities should be used as possible parameters for the measurement of the social dominance. Only the comparison among different independent rank tests could bring us to definite conclusions about social dominance.

The present experiment is a preliminary exploration of the possibility of studying the social dominance in rats, measured by several behavioral parameters. A detailed ethological description of those and other behavioral gestures in rats has been provided by Barnett, $(1967,1975)$ and by Blanchard (Blanchard \& Blanchard, 1977; Blanchard, Fukuraga, Blanchard, \& Kelley, 1975), among others. An attempt was made to identify the dominant rats in a colony by analyzing the correlation between different behavioral categories observed.

\section{METHOD}

Subjects

Twenty-seven naive male Sprague-Dawley rats, ranging in age

The author wishes to extend thanks to Claudia Boenicke for her excellent assistance and to Steve Charles for his helpful criticism of earlier versions of this paper. from 130 to 150 days at the time of testing, were housed alone in standard laboratory cages and maintained on a 12-h light-dark cycle, using a reversed light cycle and red light. Food and water were available ad lib at all times. The rats were marked with fuchsin basic dye to permit identification.

\section{Procedure}

The experimental session consisted of a $15-\mathrm{min}$ period of testing in which the isolated animals were assigned randomly to groups of three in a $50 \times 50 \times 30$ in. chamber, at the beginning of the active phase of their day-night rhythms (i.e., in the red light phase).

During pretests the observer made notes describing the behavior of the animals in their experimental situation, catalogued the different behavioral responses to the other colony animals the subjects had shown, and, as a basis for subsequent quantitative analysis, chose six of those behavioral categories that could be recognized with certainty. Three of those parameters were agonistic (attack, submission, and boxing) and another three were nonagonistic activities (grooming, mounting, and sniff ing) (Figure 1). Two possible modes of participation in each of these social behaviors were considered: winner-loser, dominantsubordinate, active-passive, mounter-mounted, and sniffersniffed. The sum of the different parameters recorded, defined as "total interaction," expresses the general bodily activity of the animal. For the final routine scoring, the incidence and duration of each parameter was recorded. In order to check on the reliability of the behavior categories, a second observer was used, and interobserver agreement was of the order of $90 \%$.

\section{RESULTS}

Table 1 shows the percentage duration of each behavioral category throughout a testing period. After the 1 st week of testing, the rats in the social colony showed a relative stabilization in most of their repertoires (the agonistic parameters lasted 67\%, 65\%, and $71 \%$ of the total time of the session, along the $2 \mathrm{nd}, 3 \mathrm{rd}$, and 4th weeks, respectively). However, a clear increase in the submission (from 3\% in the 1 st week to $32 \%$ in the last) and a decrease of the boxing and grooming were observed.

Table 2 shows the correlation among the different behavioral indices. A total of 25 significant correlation coefficients were observed among the mentioned parameters: 16 positive and 9 negative. A higher correlation was obtained within the agonistic categories than within 
Table 1

Duration (in Percentages) of Several Behavior Parameters During Each Session

\begin{tabular}{lrrrr}
\hline & \multicolumn{4}{c}{ Day } \\
\cline { 2 - 5 } \multicolumn{1}{c}{ Parameter } & 1 & 8 & 15 & 22 \\
\hline Attack & 8 & 39 & 35 & 3 \\
Submission & 3 & 22 & 22 & 32 \\
Boxing & 13 & 6 & 8 & 3 \\
Total Agonistic Behavior & 24 & 67 & 65 & 71 \\
Grooming & 12 & 3 & 4 & 2 \\
Mounting & 17 & 5 & 5 & 6 \\
Sniffing & 13 & 11 & 11 & 6 \\
Total Nonagonistic Behavior & 42 & 19 & 20 & 14 \\
Other Behavior Not Recorded & 34 & 14 & 15 & 15 \\
\hline
\end{tabular}

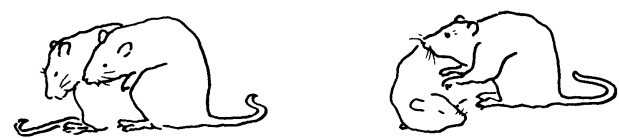

GROOMING

SUBMIT

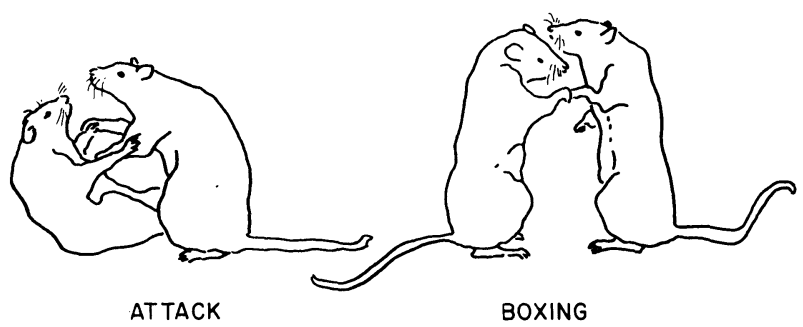

Figure 1.

Table 2

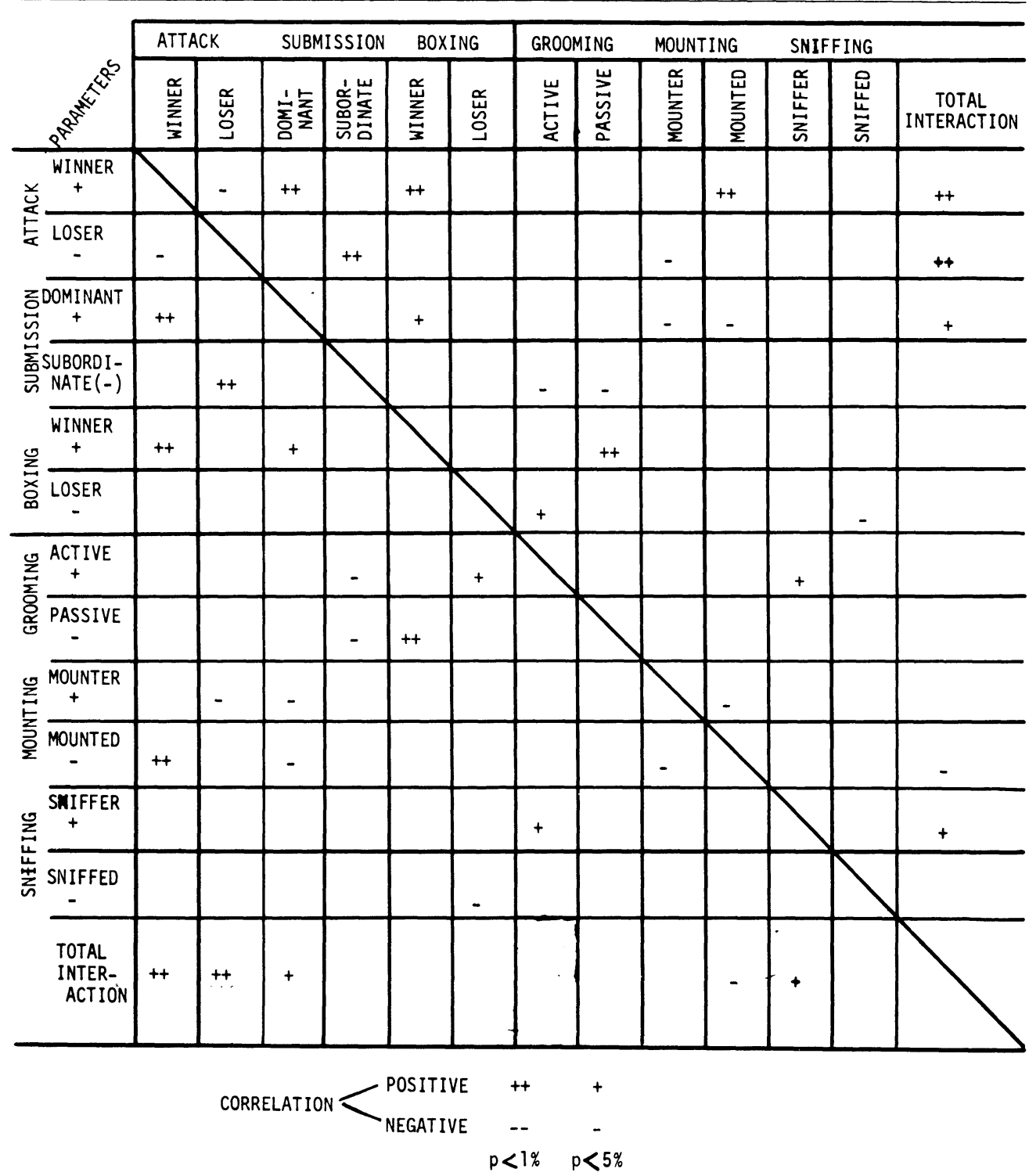


the nonagonistic. The former showed also a positive correlation with the degree of total interaction.

There was a significant correlation $(\mathrm{p}<.01)$ between the winners in attack and boxing. These also induced more submissive postures in others and frequently showed a high degree of total interaction (i.e., general bodily activity) in relation to the other members of the group. Conversely, the losers were the subordinated animals and showed almost only passive defensive. Significant differences $(p<.01)$ were found in the rank order among individuals for sniffing, mounting, attack, and submission.

\section{DISCUSSION}

The considerable increase of the submission patterns along successive sessions observed in Sprague-Dawley rats agrees with the progressive decrease of aggressive behavior reported in other strains of wild and domestic rats, Wistar, Long-Evans, and Lewis (Drews \& Wulczyn, 1975; Price \& Huck, 1976; Taylor \& Moore, 1975).

The clearly recognizable difference observed between the agonistic behavioral patterns of the dominant animals and those of the subordinate ones has been analyzed previously by Blanchard (Blanchard \& Blanchard, 1977; Blanchard, Blanchard, \& Takahashi, 1978), who studied the separation of the attack and defense reactions in rats. Earlier, and in another species, De Fries and McClearn (1970) demonstrated the quite different contribution of the dominant and subordinate male mice to the genetic constitution of the next generation.

This pilot study shows highly significant correlations among most of the different behavioral categories analyzed, mainly among the agonistic parameters. Of particular significance was the positive correlation between the winners in attack and boxing with the dominant animals in the submission category. They also showed a high level of total interaction, which supports the hypothesis of a relative high social activity in this strain of rats.

After testing the dominance position of the rat during 2-h sessions, Drews and Wulczyn (1975) reported similar results and also suggested the importance of other factors such as winning at boxing, grooming passivity, and mounting activity. However, it is felt that the present testing period of $15 \mathrm{~min}$ was too short for an exact measure and validation of those other factors.

Although the correlations found in the present experiment suggest this testing method as a viable approach to the study of the social structure in rats, they are only unequivocally representative of a specific test-bound rank order within a group of animals because there is not necessarily a uniform order of dominance for the different behaviors. Rats show a specific rank order for each function, and it does not need to correlate among them (Militzer, 1977). There is also no dependence between spontaneous behavioral and competitive induced tests (Baenninger, 1970: Boreman \& Price, 1972; Drews \& Wulczyn, 1975; Syme, 1974).

Since the social dominance in rats presents a complex hierarchical structure and the unidimensionality of dominance as a social structuring mechanism has not been proved, it seems impossible to generalize on the social behavior of the rat when measuring only a single parameter, or only a few. In order to be able to offer definite and unequivocal conclusions about social dominance in rats, therefore, it is necessary to identify the rank order within a group of animals in different independent functions and to investigate whether there is a significant correlation among the several dominance tests.

\section{REFERENCES}

BAENNINGER, L. P. Social dominance in the rat: "Spontaneous", food and water competition. Journal of Comparative and Physiological Psychology, 1970, 71, 202-209.

Barnett, S. A. Rats. Scientific American, 1967, 216, 78-85.

Barnett, S. A. The rat: A study in behavior (rev. ed.). Chicago: University of Chicago Press, 1975.

Blanchard, R. J., \& Blanchard, D. C. Aggressive behavior in the rat. Behavioral Biology, 1977, 21, 197-224.

Blanchard, R. J., Blanchard, D. C., \& Takahashi, L. K. Pain and aggression in the rat. Behavioral Biology, 1978, 23, 291-305.

Blanchard, R. J., Fukunaga, K., Blanchard, D. C., \& Kelley, M. J. Conspecific aggression in the laboratory rat. Journal of Comparative and Physiological Psychology, 1975, 25, 1204-1209.

Boreman, J., \& Price, E. O. Social dominance in wild and domestic Norway rats (Rattus norvegicus). Animal Behaviour, 1972, 20, 534-542.

De Fries, J. F., \& McClearn, G. E. Social dominance and Darwinian fitness in the laboratory mouse. American Naturalist, 1970, 104, 408-411.

Drews, D. R., \& Wulczyn, F. H. Measuring dominance in rats. Psychological Records, 1975, 25, 573-581.

Martin Ramirez, J., \& Delius, J. D. Aggressive behavior of pigeons: Suppression by archistriatal lesions. Aggressive Behavior, 1979, 5, 3-17. (a)

Martin Ramirez, J., \& Delius, J. D. Nucleus striae terminalis lesions affect agonistic behavior of pigeons. Physiology \& Behavior, 1979, 22, 871-876. (b)

Militzer, K. Methods of testing social dominance in rats. Zeitschrift für Versuchstierkunde, 1977, 19, 112.

Price, E. O., \& Huck, U. W. Open-field behavior of wild and domestic Norway rats. Animal Learning \& Behavior, 1976, 4, 125-130.

Schjelderup-Ebвe, T. Beiträge zur Biologie und Sozial- und Individuellpsychologie bei Gallus domesticus. Adler: Greifswald, 1922.

Syme, G. J. Competitive orders as measures of social dominance. Animal Behaviour, 1974, 22, 931-940.

TAYlOR, G. T., \& Moore, S. Social position and competition in laboratory rats. Journal of Comparative Physiological Psychology, 1975, 88, 424-430.

(Received for publication November 21, 1979.) 